\title{
Accounting for Variation in the Explanatory Power of the Psychometric Paradigm: The Effects of Aggregation and
}

\section{Focus}

\author{
NICOLÁS C. BRONFMAN (*) \\ Departamento de Ciencias de la Ingeniería, Universidad Nacional Andrés Bello. \\ Santiago, Chile
}

\section{LUIS ABDÓN CIFUENTES}

Departamento de Ingeniería Industrial y de Sistemas, P. Universidad Católica de Chile. Santiago, Chile

\section{MICHAEL L. DEKAY}

Department of Engineering and Public Policy, Carnegie Mellon University, Pittsburgh, PA.

\section{HENRY H. WILLIS}

RAND Corporation, Pittsburgh, PA.

\section{(*) CORRESPONDING AUTHOR}

Departamento de Ciencias de la Ingeniería, Universidad Nacional Andrés Bello. Santiago, Chile.

Avenida República 237

Postal Code: 837-0146

Phone number: 00-562-6618256

Fax: 00-562-6618623

E-mail: nbronfman@unab.cl 


\section{Abstract}

Most psychometric studies of risk perception have used data that have been averaged over participants prior to analysis. Such aggregation obscures variation among participants and inflates the magnitude of relationships between psychometric dimensions and dependent variables such as overall riskiness. However, most studies that have not averaged data over participants have also shifted the focus of analysis from differences among hazards to differences among participants. Hence, it is unclear whether observed reductions in the explanatory power of psychometric dimensions result from the change in the level of analysis or from the change in the focus of analysis. Following Willis et al.'s (2005) analysis of ecological risk perceptions, we unconfound these two variables in a study of risk perceptions in Santiago, Chile, although we use more traditional hazards, attributes, and statistical procedures. Results confirm that psychometric dimensions explain less variation in judgments of riskiness and acceptability at the disaggregate level than at the aggregate level. However, they also explain less variation when the focus of analysis is differences among participants rather than differences among hazards. These two effects appear to be similar in magnitude. A simple hybrid analysis economically represents variation among participants' judgments of hazards' riskiness by relating those judgments to a common set of psychometric dimensions from a traditional aggregate-level analysis.

Keywords: risk perception; psychometric paradigm; principal component analysis; level of analysis; aggregation 


\section{Introduction}

For the past quarter century, research on risk perception has been dominated by Slovic, Fischhoff, and Liechtenstein's psychometric paradigm (Fischhoff et al., 1978; Fischhoff et al., 1982; Slovic et al., 1980, 1985, 1986; Slovic, 1987). In the traditional method, participants rate a large number of hazards on several attributes and a few dependent measures, such as riskiness or acceptability. These ratings are averaged over participants, and the resulting hazard $\times$ attribute matrix is analyzed using either principal component analysis or common factor analysis. ${ }^{1}$ The resulting components or factors are given interpretive names (e.g., dread risk, unknown risk) and used as independent variables in regressions to predict mean ratings of riskiness or acceptability. Typically, a few components or factors account for $70-90 \%$ of the variation in these dependent variables. Studies using this approach have been conducted in Australia (Eiser et al., 1990; Rohrmann, 1994), Brazil (Nyland, 1993), Chile (Bronfman and Cifuentes, 2003), China (Jianguang, 1994), France (Bastide et al., 1989; Karpowicz-Lazerg and Mullet, 1993; Poumadere et al., 1995; Wiegman et al., 1995), Hong Kong (Keown, 1989), Hungary (Englander et al., 1986), Japan (Hinman et al., 1993; Kleinhesselink and Rosa, 1991), Norway (Teigen et al., 1988), Poland (Goszczynska et al., 1991), Sweden (Nyland, 1993; Sjöberg, 1999, 2000), the United Kingdom (Eiser et al., 1990), and the United States (Fischhoff et al., 1997; Hinman et al., 1993; Slovic, 1987), often with similar results.

\footnotetext{
${ }^{1}$ Among other differences, principal component analysis attempts to explain all of the variation in attribute ratings (including variation unique to individual attributes), whereas common factor analysis attempts to explain only the common variation (i.e., the
} 
Despite the acknowledged influence of the psychometric paradigm, research in this tradition has been criticized for its use of small and unrepresentative samples of participants; its failure to attend to the risk target (i.e., whether risk judgments are being made for one's self, for one's family, or for the general public); and its use of aggregatelevel statistical procedures that obscure variation among participants and inflate the explanatory power of the psychometric dimensions (e.g., Hermand et al., 2003; Schütz and Wiedemann, 1998; Sjöberg, 1998, 2000, 2002).

In this article, we address the first of these criticisms by using data from a representative sample of adults in Santiago, Chile. In a previous article based on the same sample, Bronfman and Cifuentes (2003) addressed the second criticism by comparing judgments of social and personal risk and judgments of social and personal benefit. The third criticism is the primary concern of this article. Our approach is modeled after analyses presented by Willis et al. (2005).

A number of methodological concerns have been raised elsewhere (Boholm, 1998; FifeSchaw and Rowe, 1996, 2000; Langford et al., 1999; Marris et al., 1997). For example, Fife-Schaw and Rowe (2000) discuss specific methodological issues that warrant consideration prior to employing the psychometric approach, namely item-presentation order, sample conditioning, reliability and validity. Regarding the first issue, they noted that question order appears to influence responses to a non-trivial degree, stating that "the magnitude of effects suggest that these are large enough to potentially obscure true differences between groups or changes over time" (p. 177). Although the authors concede to the potential of the psychometric approach when dealing with aggregated 
data from relatively large samples or subgroups, they find sufficient individual-level variability in scores to warn against adopting the technique for individuals or very small groups. One purpose of the current research is to quantify the deleterious effects of such disaggregation.

In an extensive review of the risk-perception literature, Boholm (1998) focused on several problems that arise in the comparison of psychometric studies, discussing such pertinent issues as the role of communication and the media, local political systems, and other features of societies and respondents (e.g., marginality, gender, and ethnicity). Finding little consensus on basic theoretical issues and appropriate methodologies, Boholm concluded that comparative psychometric risk-perception studies form a heterogeneous research field, and urged authors to systematize their theoretical frameworks and results in order to provide a more solid foundation for additional inquiry. The research reported here contributes to this effort by adopting a framework that encompasses and compares two distinct sources of variation in psychometric studies: differences in the level of aggregation and differences in the focus of analysis.

\subsection{Aggregation Troubles}

It has long been recognized that averaging hazard ratings over participants prior to analysis obscures variation among individuals, and that regression results from averaged data may not hold for individual participants (Gardner et al., 1982; Harding and Eiser, 1984; Vlek and Stallen, 1981). Indeed, there have been several attempts to assess the psychometric approach without averaging ratings over participants. In one such study, 
Gardner and Gould (1989) asked participants to rate six human-health hazards on four attributes (dread, catastrophic potential, number of deaths, and scientific understanding) and on overall riskiness. The authors regressed overall riskiness judgments onto the four attribute ratings separately for each hazard, and found that the attributes explained an average of $29 \%$ of the variation in the dependent measure $\left(R^{2}\right.$ range $=14 \%$ to $46 \%$, depending on the hazard and sample). Similar results have been reported frequently (Gardner et al., 1982; Harding and Eiser, 1984; Slovic et al., 1986; Sjöberg, 1996, 2000; Marris et al., 1997; Marris et al., 1998; Trumbo, 1996), although the specifics vary by study.

These studies strongly suggest that the explanatory power of the psychometric paradigm is lower when disaggregate rather than aggregate data are analyzed, but their methods differ from the traditional psychometric approach in another way as well. Specifically, the cases used in the regression analyses are participants rather than hazards. Thus, an alternative interpretation is that the psychometric dimensions are less useful for explaining differences among participants than for explaining differences among hazards. Another possibility is that the decrease in explanatory power results from both the difference in the level of analysis (disaggregate instead of aggregate) and the difference in the focus of analysis (participants instead of hazards).

\subsection{Crossing the Level and Focus of Analysis}

Although others (e.g., Gardner et al., 1982) have correctly noted that the two approaches described above answer different questions, Willis et al. (2005) were the first to document the extent of this confound in the larger risk-perception literature. 
Table 1 depicts the four possibilities that result from crossing the level and focus of analysis. The traditional psychometric approach is based on what we label aggregatelevel hazard-focused analysis in the upper left cell of the table. This approach involves a hazard $\times$ attribute matrix, with data averaged over participants prior to analysis. The resulting components or factors are used to explain how hazards differ in their riskiness or acceptability. Disaggregate-level hazard-focused analysis is similar, except that analyses are conducted separately for each participant and then summarized; the primary focus is still on differences among hazards. Individual-differences studies like those cited in the previous section often use what we label disaggregate-level participant-focused analysis in the lower right cell of the table. This approach involves a separate participant $\times$ attribute matrix for each hazard, with the resulting components or factors used to explain differences in participants' evaluations of individual hazards. Aggregate-level participant-focused analysis is similar, but data are averaged over hazards prior to analysis; the primary focus is again on differences among participants.

There have been hundreds of risk-perception studies that have used aggregate-level hazard-focused analysis, and a handful (cited above) that have used disaggregate-level participant-focused analysis. To our knowledge, only four studies have used disaggregate-level hazard-focused analyses (Bronfman and Cifuentes, 2003; Kraus and Slovic, 1988; Marris et al., 1997; Willis et al., 2005). For example, Kraus and Slovic (1988) reported that the median $R^{2}$ for predicting riskiness judgments on the basis of psychometric factors was $94 \%$ for the traditional aggregate-level hazard-focused approach (a separate analysis was conducted for each of six technology classes), but only $69 \%$ for the disaggregate-level hazard-focused approach (a separate analysis was conducted for each participant). Similarly, only three studies have used aggregate-level 
participant-focused analyses (Barnett and Breakwell, 2001; Savadori et al., 2004; Willis et al., 2005). For example, Savadori et al. (2004) reported aggregate-level participantfocused analyses for perceptions of seven biotechnology hazards. In that study, regressions designed to distinguish among participants' riskiness judgments yielded adjusted $R^{2}$ values ranging from $30 \%$ to $45 \%$, depending on the participant group (experts versus public) and hazard type (food versus medical-pharmaceutical applications). Taken together, this literature suggests that decreases in explanatory power may result from changes in either the level or the focus of analysis. Unfortunately, only five of these studies (Bronfman and Cifuentes, 2003; Kraus and Slovic, 1988; Marris et al., 1997; Slovic et al., 1986; Willis et al., 2005) have included analyses from more than one cell of Table 1, and just two (Kraus and Slovic, 1988; Willis et al., 2005) have reported regression results for riskiness judgments using analyses from more than one cell.

Willis et al. (2005) analyzed a single data set using all four methods. In their second study, 30 laypeople drawn from two school-parent organizations and one church group rated 34 ecological hazards on 17 attributes and three dependent variables (overall risk, ecological risk, and acceptability). They used common factor analysis with an oblique rotation method that allowed the factors to be correlated. In regressions for predicting judgments of overall risk, $R^{2}$ values were $81 \%$ for the traditional aggregate-level hazard-focused approach, 66\% for the aggregate-level participant-focused approach, $62 \%$ (on average) for the disaggregate-level hazard-focused approach, and $48 \%$ (on average) for the disaggregate-level participant-focused approach. Results for the other two dependent variables were qualitatively similar. These findings indicate that the decrease in explanatory power from the traditional approach resulted from changes in 
both the level of analysis and the focus of analysis. This important conclusion warrants replication in a larger sample and with commonly-used sets of risks and attributes.

The choice between hazard-focused and participant-focused analysis depends on the goals of the study. For comparative risk analysis (e.g., Jones and Klien, 1999; Minard, 1996) and risk ranking (e.g., DeKay et al., 2001; Florig et al., 2001; M.G. Morgan et al., 1996; K.M. Morgan et al., 2001; Willis et al., 2004), the primary focus is on differences among hazards. For other purposes, such as assessing attitude-behavior relationships across people, or informing the design of risk-communication materials about a specific hazard for different populations, a participant-focused approach is arguably more informative. The choice of level of analysis, however, involves a tradeoff between the desire to represent variability among participants (or hazards) and the ability to interpret and summarize data easily, among other considerations.

\subsection{Alternative Methods for Representing Individual Variation in Risk Perception}

In addition to the participant-focused analyses reported above, researchers have employed a number of other methods for characterizing individual differences in risk perception. Shortly after the introduction of the psychometric paradigm, Vlek and Stallen (1981) used a program called PRINCALS (PRINcipal Components by Alternating Least Squares) to plot vectors for individual participants' riskiness judgments in a common multidimensional space for describing differences among hazards. They conducted a parallel analysis for acceptability judgments. In effect, they used an aggregate-level method for identifying a small number of dimensions for 
describing hazards while preserving and representing variation in how participants related judgments of riskiness and acceptability to these dimensions. Wagenaar et al. (1984) subsequently used PRINCALS to map the goals of individual gamblers into a common multidimensional space of possible objectives. Arabie and Maschmeyer, (1988) used a similar program called MDPREF (MultiDimensional PREFerence analysis), which fits the same vector model as PRINCALS, to display individuals' judgments of economic risk to the U.S. economy in a common space for differentiating economic events. This vector model differs from the traditional psychometric approach in that the multidimensional space is inferred from the riskiness or acceptability judgments themselves, without the need for other rating scales.

The above approach did not catch on in the risk-perception literature, however, perhaps because of restrictions in the vector model (e.g., rotating the dimensions to a more interpretable orientation is not allowed). Recently, Willis et al. (2005) resurrected the idea of plotting individual vectors in a common hazard space, but implemented it using more familiar and flexible procedures (common factor analysis, multiple regression, and correlation). The result was a parsimonious description of the variation among hazards (using a common set of dimensions from an aggregate-level hazard-focused analysis) and variation among participants (using a different riskiness vector for each person). We present a similar analysis later in this article.

Other authors have used the INDSCAL (INDividual differences SCALing) model, which uses ratings of the similarity between items (e.g., hazards) to construct the multidimensional space. A unique feature of this model is that the common dimensions of the space are stretched or compressed to fit individual participants' data by means of salience weights. For example, Irwin et al., 1996, demonstrated that differences in 
participants' salience weights for dimensions representing a variety of HIV scenarios were related to characteristics of the participants. Although Irwin et al. (1996) did relate mean ratings of riskiness and other variables to the aggregate dimensions, they did not conduct similar analyses for individuals' riskiness vectors.

Finally, Siegrist et al., (2005) recently suggested that three-mode principal component analysis (3MPCA) is appropriate for analyzing a full participant $\times$ attribute $\times$ hazard matrix, without aggregating the data over one mode (e.g., over participants in a traditional aggregate-level hazard-focused analysis) and without conducting separate analyses for each item in one mode (e.g., for each hazard in a disaggregate-level participant-focused analysis). 3MPCA is indeed a very promising method for understanding the explanatory power of the psychometric paradigm, but there are at least two difficulties in using this approach to answer our primary questions. First, the preprocessing steps that are currently advocated (Kiers and Van Mechelen, 2001; Siegrist et al., 2005) involve centering the data within each combination of attribute and hazard by subtracting the average of participants' ratings for that combination, in order to eliminate unknown "neutral points" or "offset terms." According to Siegrist et al. (2005), "this centering takes out the very same information as was analyzed by the PCA on aggregated data" (p. 216) (i.e., by the traditional psychometric approach). Although Siegrist et al. (2005) viewed this situation as a benefit of centering, it causes great difficulties for the problem that we intend to address, because three potentially interesting sources of variation (hazards, attributes, and the hazards $\times$ attributes interactions) are removed at the outset. We cannot assess how well psychometric dimensions explain differences in the riskiness of hazards if all hazards have scores of zero on all attribute rating scales (Siegrist et al. (2005) reported components for hazards 
and rating scales, but these are fundamentally different from the components that emerge from the traditional psychometric model). Second, it is not clear how one should relate the 3MPCA components to judgments of hazards' riskiness or acceptability, even if issues of centering were resolved (e.g., even if hazard components reflected mean differences among hazards). Although Siegrist et al. (2005) related other individualdifference measures (e.g., gender, general trust) to participant components, they did not attempt to predict other judgments that vary over hazards and participants (as judgments of riskiness do) on the basis of the various components for hazards, rating scales, and participants.

So although the techniques described above have been useful for describing some aspects of variability in individuals' risk perceptions, not all of these techniques are well-suited to our goal of accounting for observed variations in the explanatory power of the traditional psychometric dimensions. In PRINCALS and MDPREF, the multidimensional space is an aggregate-level hazard-based space. In INDSCAL, salience weights yield more individualized hazard-based spaces, but the dimensions are constrained to be the same for every participant. The analysis is thus in between what we have labeled aggregate-level and disaggregate-level analyses (Kuyper and Vlek, 1984, reported an "unorthodox" disaggregate-level hazard-based use of INDSCAL, in which a separate analysis was conducted for each participant, but they did not interpret the resulting dimensions). In all of these approaches, the primary analysis is hazardbased rather than participant-based; individual differences arise only in the way that participants differentiate among hazards (in INDSCAL) or relate the features of hazards to judgments of riskiness or acceptability (in the vector model of PRINCALS or MDPREF). On the other hand, 3MPCA—as it is typically implemented—appears to be 
primarily participant-focused. Because variation over hazards and rating scales is removed at the outset, information that has traditionally be viewed as useful in understanding risk perceptions (e.g., that people have greater knowledge of the risk from bicycles than the risk from nuclear power) is excluded from the analysis.

For these reasons, adopting one of the above methods for the current study would make it difficult to relate the results to those from the principal-component and factor-analytic studies cited earlier. We have therefore chosen to use principal component analysis of traditional psychometric rating scales as the basis for assessing the effects of aggregation and focus. This choice allows us to stay as close as possible to the discrepancies in explanatory power that have been noted in the broader risk-perception literature.

\subsection{Overview of the Present Study}

The primary objective of this article is to explore the power of the classical psychometric paradigm in a manner that clearly separates differences in the level of analysis (aggregate versus disaggregate) from differences in the focus of analysis (hazards versus participants). Using a subsample of previously published data (Bronfman and Cifuentes, 2003), we disentangle the effects of level and focus by conducting analyses that correspond to each of the four cells of Table 1. Although our basic approach follows that developed by Willis et al. (2005), our study differs from theirs in several important respects, including the size and composition of the sample of participants, the sets of hazards and attributes considered by those participants, and the 
analytical techniques employed. Such differences are intended to provide insight into the generality of Willis et al.'s primary findings. 


\section{Methods}

\subsection{Materials}

Laypeople from Santiago, Chile were asked to rate 54 hazards on 12 attributes and seven dependent measures of risk, benefit, acceptability, and regulatory strictness. To make the survey task manageable for participants, these 19 rating scales were divided among four versions of the questionnaire. In each version, participants were asked to evaluate the 54 hazards on four or five scales, for a total of 216 ratings (one version) or 270 ratings (three versions). For details, see Bronfman and Cifuentes (2003).

In this article, we focus on 10 attributes that appear frequently in the psychometric literature: catastrophic potential, severity of consequences, dread, oldness, latency of effects, knowledge (on the part of the exposed population), involuntariness, control (by the exposed population), number of people exposed, and personal effect. We also restrict our analyses to two of the dependent measures: social risk and acceptability. All but one of these variables were measured on 7-point scales; social risk was measured on a 10-point scale. See Table 2 for descriptions of these 12 scales.

\subsection{Participants}

The survey was conducted in January and February, 2001. A representative sample of the 32 municipalities of Santiago was selected, considering geographical location, income, and socioeconomic status. Participants were contacted individually either at 
work or at home. Although each version of the questionnaire took only about 30 minutes to complete, single versions were left with the participants for a full day so as not to impinge upon their daily routines. Participants could request more time if necessary. They could also ask for additional versions of the questionnaire, up to the maximum of four.

A total of 508 participants returned at least one questionnaire, for an overall the response rate of $43 \%$. However, the analyses in this article are restricted to a subsample of 117 participants who returned all four versions of the questionnaire. In this subsample, the average age of participants was 34 (range $=18$ to 66). Fifty-one percent of the participants were female, $48 \%$ were single, $43 \%$ were married, and $9 \%$ were either divorced or widowed. Almost all participants (95\%) had finished high school, $62 \%$ had some university studies, $75 \%$ were employed, $9 \%$ were unemployed, and $13 \%$ were students. Monthly household income ranged from US\$1,000 to US\$1,286 (in 2001 dollars). These statistics are similar to those for the full sample (Bronfman and Cifuentes, 2003) and consistent with official statistics for Santiago, except for the slightly elevated educational level among participants. 


\section{Results}

\subsection{Hazard-Focused Analyses: Differences among Hazards}

The analyses reported in this section concern differences among hazards. These differences are considered first at the aggregate level (after averaging ratings over participants) and then at the disaggregate level (with separate analyses for each participant).

\subsubsection{Aggregate-Level Hazard-Focused Analyses}

Using the traditional psychometric approach, we averaged responses over the 117 participants to produce mean ratings for each of the 54 hazards on each of the 12 scales (10 attributes and two dependent variables). We then performed a principal component analysis on the hazard $\times$ attribute matrix (not including the two dependent variables), retaining components with eigenvalues greater than 1.0 and rotating the solution using the orthogonal varimax method. The resulting four-component solution explained $93 \%$ of the total variance in attribute ratings (see Table 3 ).

The attributes catastrophic potential, severity of consequences, and dread all had very high positive loadings on Component 1 , which accounted for $37 \%$ of the variance. We labeled this component catastrophic potential. We prefer this label over the more frequently used dread risk because it refers to more tangible features of the risks themselves (Jenni, 1997). Component 2, which we labeled knowledge, included oldness, latency of effects (with a negative loading), and knowledge, and accounted for $27 \%$ of 
the variance. Component 3 included involuntariness and control (with a negative loading), and accounted for $15 \%$ of the variance. We labeled this component involuntariness. The final component included number of people exposed and personal effect, and accounted for $13 \%$ of the variance. This component has been variously referred to in literature as number of exposed people (Fischhoff et al., 1978; Slovic, 1987), social and personal exposure (Slovic et al., 1985), or personal effect (Bronfman and Cifuentes, 2003). In this article, we use the term social and personal exposure because it better captures the two attributes that load on the component. Communalities for the individual attributes ranged from $85 \%$ to $97 \%$, indicating that the four components accounted for the great majority of the variance in every attribute (see the last column of Table 3). These results are similar to those observed for the entire sample of 508 participants, except that components 1 and 3 were collapsed into a single component in the larger sample (Bronfman and Cifuentes, 2003). One plausible explanation for this difference is that participants who completed all four versions of the survey took the task more seriously and made more reliable distinctions among attributes when rating the hazards.

In order to evaluate the usefulness of the four components, we regressed mean ratings for the two dependent variables (social risk and acceptability) onto the four component scores for the 54 hazards (see Section 1 of Table 4). The four components predicted judgments of social risk and acceptability very well, with adjusted $R^{2}$ values of $87 \%$ and $74 \%$, respectively. Social risk was higher for hazards with greater catastrophic potential (Component 1), for hazards that were unknown (Component 2), and for hazards with greater social and personal exposure (Component 4), but was not significantly greater for involuntary hazards (Component 3). As might be expected, the signs for all four 
components were reversed when acceptability was the dependent variable. These results are consistent with those from previous psychometric research, although results for the relationship between knowledge and riskiness have been mixed (for discussions, see K.M. Morgan et al., 2001 and Willis et al., 2005).

Figure 1 illustrates how social risk was related to each of the four components, with larger dots representing hazards with greater social risk. The left panel indicates that hazards that were rated high on catastrophic potential and social and personal exposure (the two best predictors) were also judged as being very risky, whereas the right panel indicates that knowledge and involuntariness were not strongly related to judged social risk. However, knowledge predicted acceptability better than it predicted social risk (see Section 1 of Table 4).

\subsubsection{Disaggregate (Participant-Level) Hazard-Focused Analyses}

We also performed similar hazard-focused analyses separately for each participant, after excluding 30 participants who did not rate all 54 hazards on all 10 attributes. For each of the remaining 87 participants, we performed a principal component analysis on his or her hazard $\times$ attribute matrix. Although the eigenvalues for these participant-level analyses did not always indicate four-component solutions, we retained four components to facilitate comparisons with the aggregate-level results. Components extracted from these participant-level analyses did not share common orientations (in part because the participant-level data were noisier than the aggregate-level data), and we did not attempt to interpret the results for each participant. The four-component solutions accounted for an average of $76 \%$ of the total variance in attribute ratings, with 
a range of $62 \%$ to $86 \%$ over participants. The average value was 17 percentage points lower than the value obtained in the aggregate-level principal component analysis.

For each participant, we regressed judgments of social risk and acceptability onto the four component scores for the 54 risks. On average, these models accounted for $49 \%$ of the variance in social risk (range $=8 \%$ to $79 \%$ for 85 participants) and $39 \%$ of the variance in acceptability (range $=0 \%$ to $82 \%$ for 83 participants) (see Section 2 of Table 4). These values were 38 and 35 percentage points lower than the corresponding values from the aggregate-level regression analyses, probably because of the greater variability in the participant-level data. Mean regression coefficients are not reported in Section 2 of Table 4 because the components did not have the same meaning for each participant.

\subsection{Participant-Focused Analyses: Differences among Participants}

The hazard-focused analyses above demonstrate that the explanatory power of the psychometric model decreases when the data are not averaged over participants at the outset (i.e., when disaggregate-level rather than aggregate-level analyses are used). In other studies, however, the focus of disaggregate-level analyses has often been on differences among participants rather than differences among hazards. The analyses reported in this section concern differences among participants. These differences are considered first at the aggregate level (after averaging ratings over hazards) and then at the disaggregate level (with separate analyses for each hazard). 


\subsubsection{Aggregate-Level Participant-Focused Analyses}

At the aggregate level, we calculated mean attribute ratings by averaging over hazards instead of over participants. We analyzed the resulting participant $\times$ attribute matrix using the same principal component methods used in the aggregate-level hazard-focused analysis, retaining components with eigenvalues greater than 1.0 and rotating the solution with the varimax method. The resulting four-component solution explained $66 \%$ of the total variance in attribute ratings (see Table 5).

The attributes dread, severity of consequences, and catastrophic potential all loaded on Component 1, which accounted for $27 \%$ of the variance. We again labeled this component catastrophic potential. Component 2 was very similar to Component 4 from the earlier hazard-focused analysis, with number of people exposed and personal effect having positive loadings. This component, which we called social and personal exposure, accounted for $15 \%$ of the variance. Despite the similarity between these two components and those from the earlier hazard-focused analysis, the new components describe differences among participants (after averaging across hazards) rather than differences among hazards (after averaging across participants). Thus, participants with higher scores on the first two components believed that (on average) the hazards in the questionnaires have serious consequences.

Component 3 included knowledge (with a negative loading) and involuntariness, and accounted for $14 \%$ of the variance. Component 4 included latency of effects and control, and accounted for $10 \%$ of the variance. These two components may be viewed as mixtures of the knowledge and involuntariness components from the earlier hazardfocused analysis. For Component 3, participants who thought that the exposed 
population does not know much about hazards also thought that hazards are generally involuntary. For Component 4, participants who believed that hazards usually have delayed effects also reported that it is easier for the exposed populations to avoid the risks associated with hazards. Although these new mixtures may make some sense, we chose not to provide interpretive labels for these components.

Oldness was the only attribute that did not load highly on any component. Indeed, the four components accounted for only $32 \%$ of the variance for that attribute. For the remaining attributes, communalities ranged from $61 \%$ to $81 \%$ (see the last column of Table 5).

Section 3 of Table 4 shows the results from regressing participants' mean judgments of social risk and acceptability (averaged over hazards) onto the component scores from the aggregate-level participant-focused analysis. The four components accounted for $50 \%$ of the variance in social risk and $34 \%$ of the variance in acceptability. The first two components, catastrophic potential and social and personal exposure, were significant predictors in both regressions. Participants who thought that the hazards in the questionnaire were likely to have serious consequences also rated the hazards as generally high in social risk and low in acceptability. Components 3 and 4 were not significantly related to either dependent measure.

Figure 2 illustrates how social risk was related to catastrophic potential and social and personal exposure, with larger dots representing participants who judged the hazards as being more socially risky, relative to other participants. Although this figure appears very similar to the left panel of Figure 1, the results are not directly comparable. Figure 2 reflects differences among participants, not differences among hazards. 


\subsubsection{Disaggregate (Hazard-Level) Participant-Focused Analyses}

We also performed a principal component analysis on the participant $\times$ attribute matrix separately for each of the 54 hazards, again retaining four components to facilitate comparisons. The resulting components explained an average of $61 \%$ of the total variance in attribute ratings, with a range of $54 \%$ to $66 \%$ over hazards. The average value was just 4 percentage points lower than the value obtained in the aggregate-level participant-focused analysis.

For each hazard, we regressed judgments of social risk and acceptability onto the four component scores. On average, these models accounted for $27 \%$ of the variance in social risk (range $=3 \%$ to $54 \%$ ) and $18 \%$ of the variance in acceptability (range $=2 \%$ to $50 \%$ ) (see Section 4 of Table 4). These values were 23 and 16 percentage points lower than the corresponding values from the aggregate-level participant-focused regression analyses. As before, mean regression coefficients are not reported in Section 4 of Table 4 because the components did not have the same meaning for each hazard.

\subsection{Summary of Analyses that Differ in Level and Focus}

In the previous sections, we conducted principal component analyses focusing on two different sources of variation in attribute ratings and at two different levels of aggregation. We then used the component scores from each of these analyses to predict judgments of social risk and acceptability. As expected, regardless of whether the focus was on differences among hazards or differences among participants, the proportion of variance in social risk and acceptability that was explained by the components was lower in the disaggregate analyses than in the aggregate analyses. In addition, the shift 
from hazard-focused analyses to participant-focused analyses resulted in a comparable decrease in explanatory power.

These results are depicted in Figure 3, which shows the adjusted $R^{2}$ values for predicting social risk (left panel) and acceptability (right panel) for the four different combinations of the level and focus of analysis. In both panels, the downward slopes of the lines reflect the lower explanatory power of disaggregate-level analyses relative to aggregate-level analyses. Also in both panels, the differences between the upper and lower lines reflect the lower explanatory power of analyses that focus on differences among participants relative to those that focus on differences among hazards. This pattern of results is remarkably similar to that reported by Willis et al. (2005).

The high levels of explanatory power for aggregate-level hazard-focused analyses replicate those often found with the traditional psychometric approach. At the other extreme, the relatively low levels of explanatory power for disaggregate (hazard-level) participant-focused analyses are similar to those often reported by critics of the traditional approach. However, it would be incorrect to attribute this decrease entirely to a change in the level of analysis; the change in the focus of analysis seems to play an equally important role.

\subsection{A Hybrid Hazard-Focused Analysis: Using Aggregate-Level Components to Predict Individuals’ Judgments}

In comparative risk analysis, it is very useful to differentiate hazards by describing them in terms of a common set of attributes. However, even when hazards are described using the same criteria, individuals may disagree about the relative riskiness or acceptability 
of hazards, and it is important not to dismiss such variation. Although we have reported hazard-focused analyses at both the aggregate and disaggregate levels, neither analysis is completely satisfactory. The aggregate approach yields interpretable components, but averaging prior to analysis washes away useful information about the variability among individuals. The disaggregate approach retains individual variation, but performing separate analyses for each participant is inefficient and yields results that are not easily summarized. Following the lead of others (Arabie and Maschmeyer, 1988; Vlek and Stallen, 1981; Wagenaar et al., 1984; Willis and DeKay, 2005; Willis et al., 2005), we conducted a hybrid analysis designed to represent each individual's judgments regarding the riskiness of hazards (thereby attending to variation among participants) in terms of a common set of dimensions for describing those hazards (thereby retaining interpretability).

For each participant, we computed the correlations between his or her judgments of social risk and the component scores of the 54 hazards on each of the four components from the aggregate-level hazard-focused analysis in Table 3. These correlations were then used as coordinates to plot the endpoint of each participant's social-risk vector in the aggregate-level component space. The results are depicted in Figure $4 .^{2}$ In this analysis, each participant's social-risk vector has a length of 1.0. The points (open circles) in Figure 4 are projections of the endpoints of these vectors onto two of the planes defined by the four orthogonal components. Long projections (those with endpoints far from the origin) indicate that social-risk judgments are closely related to

\footnotetext{
${ }^{2}$ Construction of the plots is only slightly more complicated if the components or factors are oblique (as in Willis et al., 2005) rather than orthogonal. In the oblique case, the vertical coordinate is given by $r_{2} / \sin \theta-r_{1} / \tan \theta$, where $\theta$ is the angle between the two components and $r_{1}$ and $r_{2}$ are the correlations between a participants' riskiness judgments and the horizontal and nonhorizontal components, respectively.
} 
one or both of the components that define the axes, whereas short projections (those with endpoints close the origin) indicate that social-risk judgments are not closely related to either component. In each panel, the average of the participants' vector endpoints is shown with a filled circle.

The left panel of Figure 4 shows that the social-risk vectors for almost all of the participants point toward the upper right quadrant of the plane formed by catastrophic potential (Component 1) and social and personal exposure (Component 4). In general, participants agreed that social risk was greater for hazards with high scores on these two components, although the spread of points indicates substantial variation among participants in the strength of these relationships. A few participants had negative correlations between social risk and one of these components, but these were usually very small. In the right panel, participants' social-risk vectors point in all directions, indicating that participants did not agree about how social risk was related to knowledge (Component 2) or involuntariness (Component 3). Many of the vector endpoints were very near the origin, indicating weak, nonsignificant relationships. Graphs for acceptability (not shown) were similar, except that the directions of the vectors were reversed, and there was a noticeable positive relationship between acceptability and knowledge (Component 2).

We also conducted analogous regressions separately for each participant. Specifically, we regressed judgments of social risk and acceptability for the 54 hazards onto the component scores from the aggregate-level hazard-focused principal component analysis in Table 3. Except for tiny differences resulting from missing data, the mean coefficients from these analyses corresponded exactly to those reported for the 
aggregate-level analysis in Section 1 of Table 4. On average, the aggregate-level components accounted for $43 \%$ of the variation in individuals' judgments of social risk (range $=3 \%$ to $71 \%$ for 113 participants) and $37 \%$ of the variation in individuals' judgments of acceptability (range $=6 \%$ to $71 \%$ for 105 participants). Relative to the fully disaggregate hazard-focused regressions reported in Section 2 of Table 4, these percentages represent decreases of only 6.5 and 2.3 percentage points for social risk and acceptability, respectively. Thus, the aggregate-level components performed almost as well as components that were determined separately for each participant.

These results illustrate how differences in hazards' aggregate-level component scores can provide useful information about individuals' judgments of social risk and acceptability for those hazards. In particular, the regression coefficients from the aggregate-level analyses in Section 1 of Table 4 accurately reflect the central tendency of participants' social-risk and acceptability judgments with respect to hazards' characteristics. The advantage of the hybrid approach is that it reveals the variability among individuals' judgments, without sacrificing the interpretability of the common dimensions. 


\section{Discussion}

The main findings of this study are straightforward and unambiguous. First, the results of the aggregate-level hazard-focused analyses replicated those from other studies that have used the traditional psychometric approach. In particular, averaging ratings over participants before conducting these analyses led to components that explained a very high percentage of the variation in mean judgments of the social risk and acceptability of hazards (adjusted $R^{2}=87 \%$ and $74 \%$, respectively).

Second, the results of the disaggregate (hazard-level) participant-focused analyses replicated those of authors who have criticized the traditional approach. The explanatory power of the psychometric dimensions was indeed much lower when data were not averaged over participants prior to analysis (mean adjusted $R^{2}=27 \%$ for social risk and $18 \%$ for acceptability).

Third, this decrease in explanatory power was only partially attributable to analyzing the data at the disaggregate level rather than the aggregate level. Focusing on differences among participants instead of differences among hazards played a roughly equal role (see Table 4 and Figure 3). Apparently, the psychometric dimensions do a better job of accounting for differences among hazards than differences among people, perhaps because agreement among participants leads to a lack of variation in either the predictor variables or dependent variables for certain hazards (Kraus and Slovic, 1988; Slovic et al., 1986). Alternatively, the difference may simply reflect the fact that the rating scales in question were originally intended to measure perceived differences among hazards, not differences among respondents. Either way, these results are 
inconsistent with suggestions that the reduction in explanatory power is primarily the result of differences in aggregation (Gardner and Gould, 1989; Sjöberg, 1996).

Fourth, the hybrid approach illustrated in Figure 4 is a useful way of representing individual variation in riskiness and acceptability judgments in terms of a common set of interpretable components. This approach is particularly appropriate in comparative risk assessment and risk ranking, where a common set of attributes is essential for developing consistent materials for describing hazards and for structuring discussions about the relative riskiness or acceptability of hazards. The required analyses are only slightly more difficult than those for the traditional aggregate-level approach, and can be conducted even if the aggregate-level hazard $\times$ attribute matrix is pieced together from different questionnaire versions in which each participant provides ratings of hazards on a subset of attributes. Finally, the regression results reported for the hybrid approach indicate that the components from the traditional aggregate-level hazardfocused analysis predicted individual participants' social-risk and acceptability judgments almost as well as the disaggregate (participant-level) components did. For these reasons, hybrid analyses appear to represent a very pragmatic balance of analytical effort, explanatory power, and interpretability. 


\section{Limitations}

As in other psychometric studies of risk perception, some reported results may be sensitive to the hazards and attributes selected for study. In particular, our set of traditional psychometric attributes omitted attributes specifically related to ecological hazards (Lazo et al., 2000; McDaniels et al., 1995, 1996; McDaniels et al., 1997; Willis et al., 2005) or interference with nature (Böhm and Pfister, 2000; Böhm, 2003; Brown et al., 2005; Bulte et al., 2005; DeKay and McClelland, 1996; Kahneman and Ritov, 1994; Sjöberg, 2000).

Although participants were not randomly sampled from the general population in Santiago, Chile, the sample was reasonably representative of that population on all demographic variables except for education. General results for the traditional aggregate-level hazard-based psychometric analyses were very similar to those that have been reported for other countries, but caution should still be used when considering results for specific hazards.

We do not believe that the primary results regarding the explanatory power of psychometric rating scales are particularly sensitive to the above limitations. It seems likely that explanatory power will be lower for disaggregate and participant-focused analyses, regardless of the specific participants, hazards, and attributes used. Even so, it is worth considering whether any omitted attributes might do a better job of explaining differences among participants than differences among hazards.

Finally, we did not consider how other characteristics of participants might be related to differences in their ratings of hazards' riskiness and acceptability. Such issues have 
been addressed elsewhere (e.g., Bouyer et al., 2001; Dake, 1991; Dosman et al., 2001; Flynn et al., 1994; Peters and Slovic, 1996; Sjöberg and Wåhlberg, 2002; Willis and DeKay, 2005). Although the addition of individual-difference variables would probably increase the total amount of variance explained in our participant-focused analyses, such increases would not undermine our conclusions regarding the explanatory power of psychometric dimensions. 


\section{Conclusions}

Psychometric dimensions do explain less variation in judgments of riskiness and acceptability at the disaggregate level than at the aggregate level. However, they also explain less variation when the focus of analysis is differences among participants rather than differences among hazards. These two effects appear to be similar in magnitude.

When the primary focus is on differentiating among hazards, as in comparative risk analysis, it is still possible to represent and quantify variation among participants in the ways that they relate the characteristics of hazards to judgments of the riskiness and acceptability of those hazards. The hybrid approach utilized in this article illustrates how this is easily accomplished within the traditional psychometric paradigm, but other methods are also available.

This study is only the second to examine the explanatory power of the classical psychometric paradigm by disentangling the level of analysis (aggregate versus disaggregate) and the focus of the analysis (differences among hazards versus differences among participants). Our results corroborate and extend the findings of Willis et al. (2005) using a larger, more diverse sample of participants; a more traditional set of hazards (as opposed to ecological hazards); a more traditional set of attributes (as opposed to attributes developed specifically for ecological hazards); and a more traditional analytical technique (orthogonal principal component analysis instead of oblique factor analysis). The striking similarity of findings across such differences suggests that Willis et al.'s (2005) conclusions may be generalized to a much broader body of risk-perception research. 


\section{Acknowledgments}

This research was partially funded by Chile's Conicyt through the National Fund for Scientific and Technological Research (Fondecyt), grant 1020501. Additional support was provided by Conicyt in the form of a Doctoral Thesis Scholarship to Nicolás Bronfman. We extend special thanks to Virna Gutiérrez for her assistance with the survey analysis and to Alex Crawford for many valuable discussions over the course of this research project. 
Table 1. Differentiating the Level and Focus of Analysis in Psychometric Studies of Risk Perception

\begin{tabular}{|c|c|c|}
\hline \multirow[b]{2}{*}{ Level of Analysis } & \multicolumn{2}{|c|}{ Focus of Analysis } \\
\hline & Differences among Hazards & Differences among Participants \\
\hline \multirow{5}{*}{ Aggregate } & Aggregate-Level Hazard-Focused & Aggregate-Level Participant-Focused \\
\hline & The traditional psychometric approach; & Based on a participant $\times$ attribute rating \\
\hline & based on a hazard $\times$ attribute rating & matrix created by averaging responses \\
\hline & matrix created by averaging responses & over hazards. \\
\hline & over participants. & \\
\hline \multirow{3}{*}{ Disaggregate } & Disaggregate-Level Hazard-Focused & Disaggregate-Level Participant-Focused \\
\hline & Based on a separate hazard $\times$ attribute & Based on a separate participant $x$ \\
\hline & rating matrix for each participant. & attribute rating matrix for each hazard. \\
\hline
\end{tabular}

Adapted from Willis et al. (2005). 
Table 2. Definitions of Attributes and Dependent Variables

Scale Endpoints

\begin{tabular}{|c|c|c|c|}
\hline & & & \\
\hline Scale & Description of Scale & Low (1) & High (7) \\
\hline Oldness & $\begin{array}{l}\text { The risk associated with each activity, substance or technology: is } \\
\text { it new and unfamiliar, or is it old and familiar? }\end{array}$ & New & Old \\
\hline Involuntariness & $\begin{array}{l}\text { To what extent is the population exposed to the risk associated with } \\
\text { each activity, substance or technology voluntarily? }\end{array}$ & Voluntary & Involuntary \\
\hline Catastrophic & To what magnitude does this activity, substance or technology have & Very small & Very high \\
\hline Potential & the potential to cause death and catastrophic destruction? & catastrophic potential & catastrophic potential \\
\hline Dread & $\begin{array}{l}\text { Is the risk associated with each activity, substance or technology, a } \\
\text { common or a terrible risk? }\end{array}$ & $\begin{array}{l}\text { Common } \\
\text { People are accustomed to } \\
\text { living with it and think } \\
\text { about it reasonably calmly. }\end{array}$ & $\begin{array}{l}\text { Dread } \\
\text { People are terrified by it. }\end{array}$ \\
\hline $\begin{array}{l}\text { Latency of } \\
\text { Effects }\end{array}$ & $\begin{array}{l}\text { Are the effects of the risk associated with each activity, substance } \\
\text { or technology immediate, or do they occur later on? }\end{array}$ & Occur immediately & $\begin{array}{l}\text { Occur far away } \\
\text { in the future }\end{array}$ \\
\hline $\begin{array}{l}\text { Severity of } \\
\text { Consequences }^{\mathrm{a}}\end{array}$ & $\begin{array}{l}\text { Should the risk associated with this activity, substance or } \\
\text { technology occur, how likely is it to produce fatal consequences? }\end{array}$ & Nonfatal & Fatal \\
\hline Knowledge $^{a}$ & $\begin{array}{l}\text { How aware is the exposed population of the risk associated with } \\
\text { each activity, substance or technology? }\end{array}$ & No knowledge & $\begin{array}{l}\text { High level of } \\
\text { knowledge }\end{array}$ \\
\hline Control & $\begin{array}{l}\text { To what extent could the exposed population avoid the risk } \\
\text { associated with each activity, substance or technology? }\end{array}$ & Not controllable & $\begin{array}{l}\text { Completely } \\
\text { controllable }\end{array}$ \\
\hline $\begin{array}{l}\text { Number of } \\
\text { People Exposed }\end{array}$ & $\begin{array}{l}\text { How many people, do you think, in the country are exposed to the } \\
\text { risks associated with each activity, substance or technology? }\end{array}$ & Very few people & $\begin{array}{l}\text { Great number } \\
\text { of people }\end{array}$ \\
\hline Personal Effect & $\begin{array}{l}\text { To what extent are you affected personally by the risk associated } \\
\text { with each activity, substance or technology? }\end{array}$ & Doesn't affect me & Affects me \\
\hline Social Risk ${ }^{b}$ & $\begin{array}{l}\text { How much risk from each activity, substance or technology is the } \\
\text { population of the country subject to? }\end{array}$ & No risk & High risk \\
\hline Acceptability & $\begin{array}{l}\text { How acceptable is the risk from each activity, substance or } \\
\text { technology to which the Chilean population is subjected? }\end{array}$ & Unacceptable & Acceptable \\
\hline
\end{tabular}

${ }^{\mathrm{a}}$ The endpoints for this attribute have been reversed for ease of exposition. ${ }^{\mathrm{b}}$ Ratings for this variable were made on a 10-point scale rather than a 7-point scale. 
Table 3. Rotated Component Pattern for the Aggregate-Level Hazard-Focused Analysis

\begin{tabular}{|c|c|c|c|c|c|}
\hline \multirow[b]{2}{*}{ Attribute } & $\begin{array}{l}\text { Component } 1 \\
\text { Catastrophic }\end{array}$ & Component 2 & Component 3 & $\begin{array}{c}\text { Component } 4 \\
\text { Social and Personal }\end{array}$ & \\
\hline & Potential & Knowledge & Involuntariness & Exposure & Communality \\
\hline Catastrophic Potential & 0.937 & -0.130 & 0.167 & 0.215 & 0.970 \\
\hline Severity of Consequences & 0.922 & 0.217 & 0.074 & -0.045 & 0.905 \\
\hline Dread & 0.906 & -0.064 & 0.337 & -0.015 & 0.938 \\
\hline Oldness & -0.087 & 0.905 & -0.138 & 0.029 & 0.846 \\
\hline Latency of Effects & 0.066 & -0.882 & -0.215 & 0.286 & 0.910 \\
\hline Knowledge & 0.273 & 0.842 & -0.358 & -0.111 & 0.924 \\
\hline Involuntariness & 0.196 & -0.133 & 0.931 & 0.208 & 0.966 \\
\hline Control & -0.304 & 0.039 & -0.900 & -0.061 & 0.907 \\
\hline Number of People Exposed & 0.136 & -0.104 & -0.018 & 0.971 & 0.973 \\
\hline Personal Effect & -0.044 & -0.140 & 0.329 & 0.901 & 0.942 \\
\hline Proportion of Variance & 0.372 & 0.274 & 0.147 & 0.134 & 0.927 \\
\hline Explained & & & & & \\
\hline
\end{tabular}

Note: Loadings greater than 0.6 or less than -0.6 appear in bold. 
Table 4. Regression Results for Hazard-Focused and Participant-Focused Analyses at Both Aggregate and Disaggregate Levels

\section{Hazard-Focused Analyses}

Component 1 Component 2 Component 3 Component 4

Catastrophic Social and

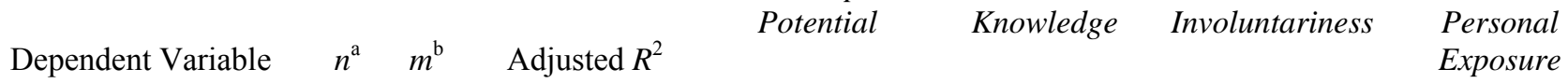

1. Aggregate Level

$\begin{array}{llllllll}\text { Social Risk } & 1 & 54 & 0.867 & 1.32^{* * * *} & -0.18^{*} & -0.07 & 0.66^{* * * *} \\ \text { Acceptability } & 1 & 54 & 0.743 & -0.79^{* * * *} & 0.36^{* * * *} & 0.06 & -0.35^{* * * *}\end{array}$

2. Disaggregate

Level

(Participant Level)

Social Risk $\quad 85 \quad 54 \quad 0.491^{\mathrm{c}}$

$(0.082-0.794)^{\mathrm{d}}$

Acceptability $\quad 83 \quad 54 \quad 0.392^{\mathrm{c}}$

$(0.000-0.824)^{\mathrm{d}}$

\section{Participant-Focused Analyses}

Component 1 Component 2 Component 3 Component 4

Catastrophic Social and

Potential Personal Unnamed Unnamed

Dependent Variable $\quad n^{\mathrm{a}} \quad m^{\mathrm{b}} \quad$ Adjusted $R^{2}$

Exposure

3. Aggregate Level

\begin{tabular}{|c|c|c|c|c|c|c|c|}
\hline Social Risk & 1 & 117 & 0.499 & $0.64^{* * * *}$ & $0.72^{* * * *}$ & 0.03 & -0.09 \\
\hline Acceptability & 1 & 117 & 0.337 & $-0.31^{* * * *}$ & $-0.38^{* * * *}$ & -0.06 & 0.09 \\
\hline
\end{tabular}

4. Disaggregate

Level

(Hazard Level)

Social Risk

$54 \quad 117 \quad 0.267^{\mathrm{c}}$

$(0.030-0.537)^{\mathrm{d}}$

Acceptability

$\begin{array}{lll}54 & 117 \quad 0.177^{\mathrm{c}}\end{array}$

$(0.019-0.503)^{\mathrm{d}}$

Note: Regression coefficients are not shown for disaggregate-level analyses because the components do not share a common interpretation.

${ }^{a} n$ is the number of regression analyses of each type; it is equal to the number of participants in Section 2 and the number of hazards in Section 4 . $^{\mathrm{b}} \mathrm{m}$ is the number of cases used in each regression; it is equal to the number of hazards in Sections 1 and 2 and the number of participants in Sections 3 and $4 .{ }^{c}$ Mean value over all regressions of the same type. ${ }^{\mathrm{d}}$ Range expressed as (Minimum-Maximum).

${ }^{*} p<0.05 .{ }^{* * * *} p \leq 0.0001$. 
Table 5. Rotated Component Pattern for the Aggregate-Level Participant-Focused Analysis

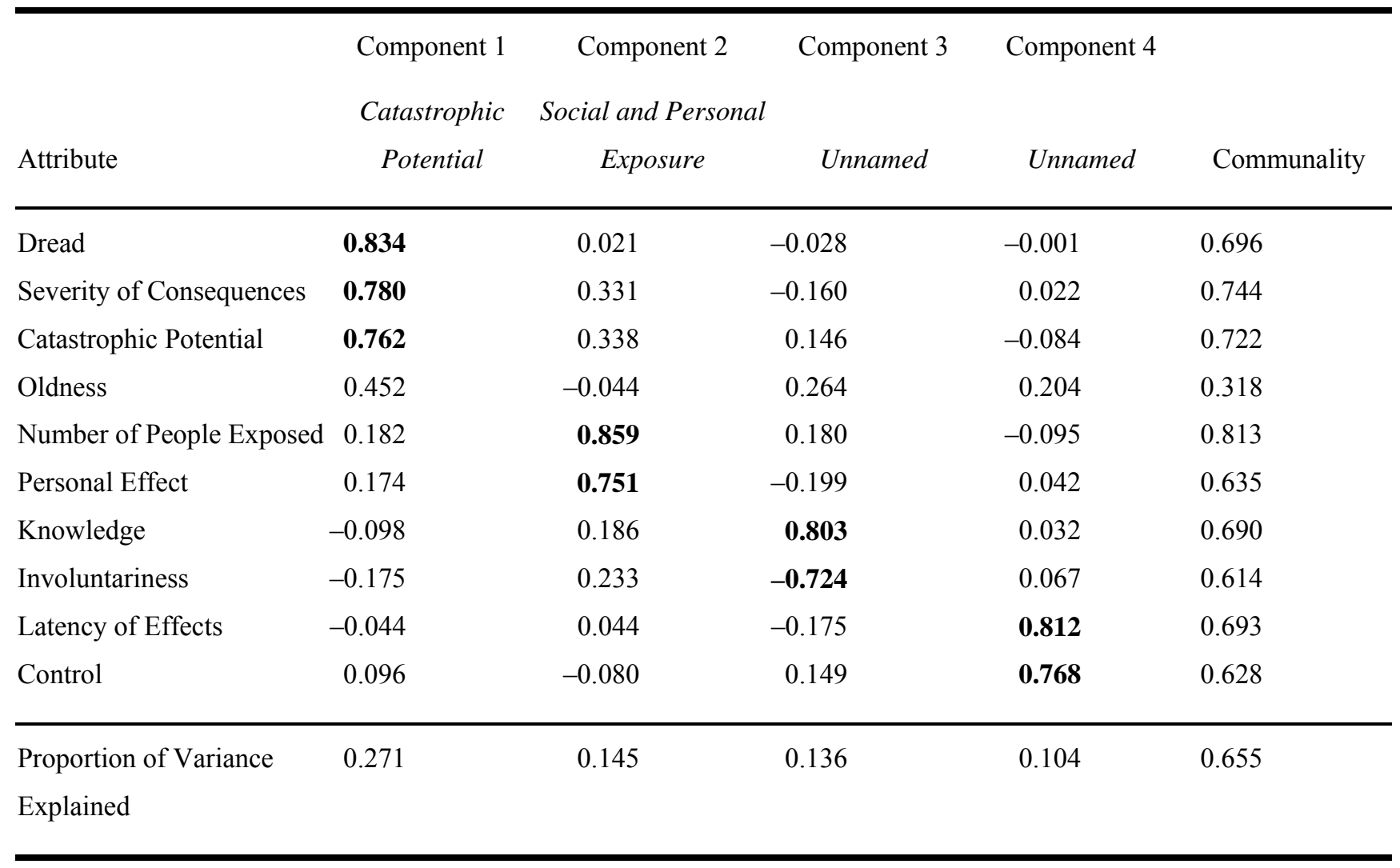

Note: Loadings greater than 0.6 or less than -0.6 appear in bold. 

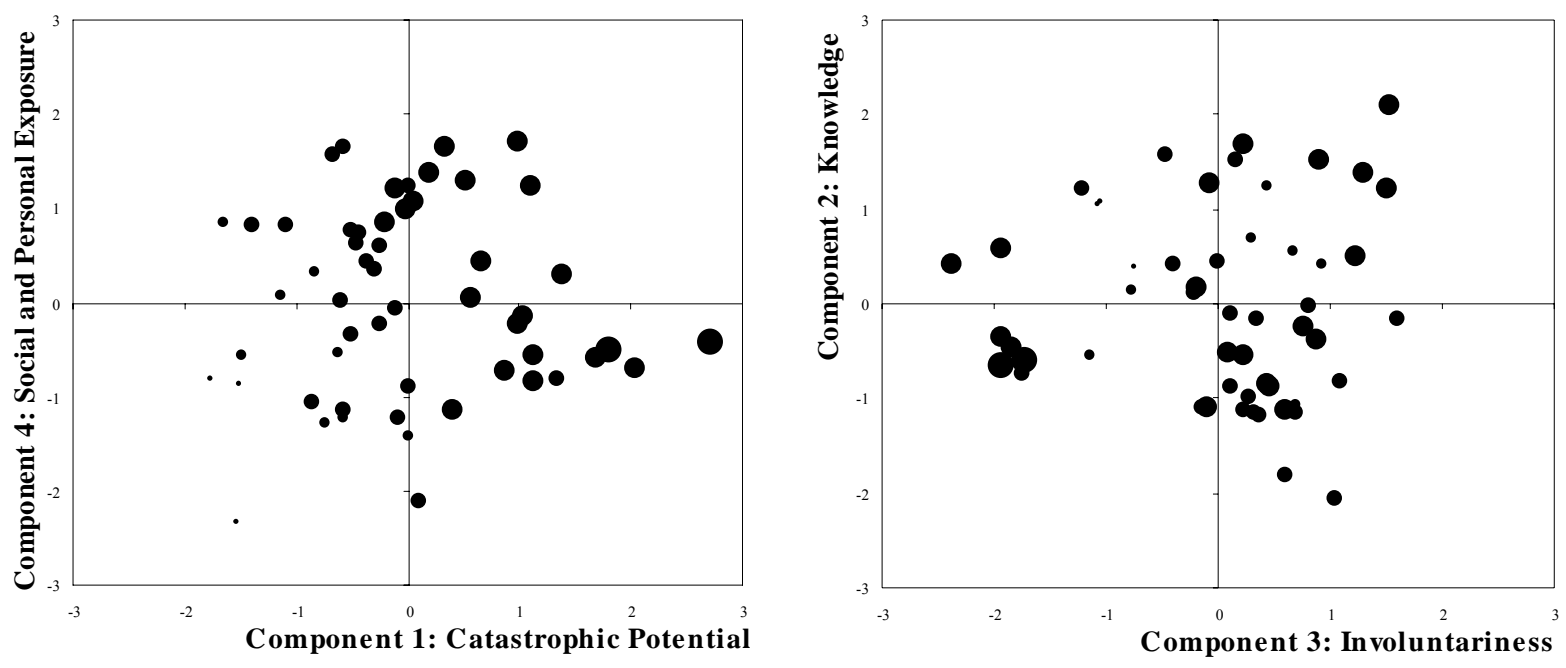

Figure 1. Locations of individual hazards in the psychometric space obtained from the traditional aggregate-level hazard-focused principal component analysis (i.e., after averaging ratings over participants). Larger dots indicate hazards that were rated as more socially risky, relative to other hazards. 


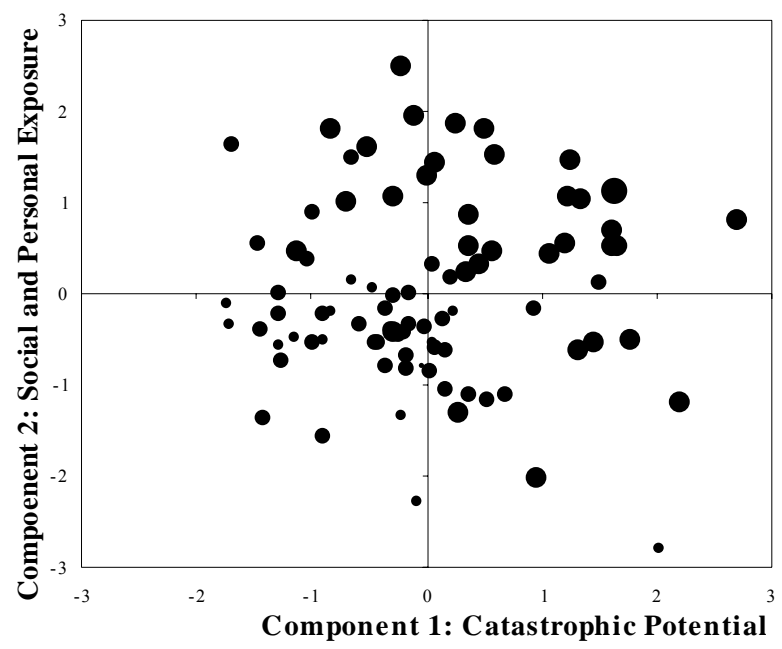

Figure 2. Locations of individual participants in the psychometric space obtained from the aggregate-level participant-focused principal component analysis (i.e., after averaging ratings over hazards). Larger dots indicate participants who rated hazards as more socially risk, relative to other participants. Only the first two components are shown. 

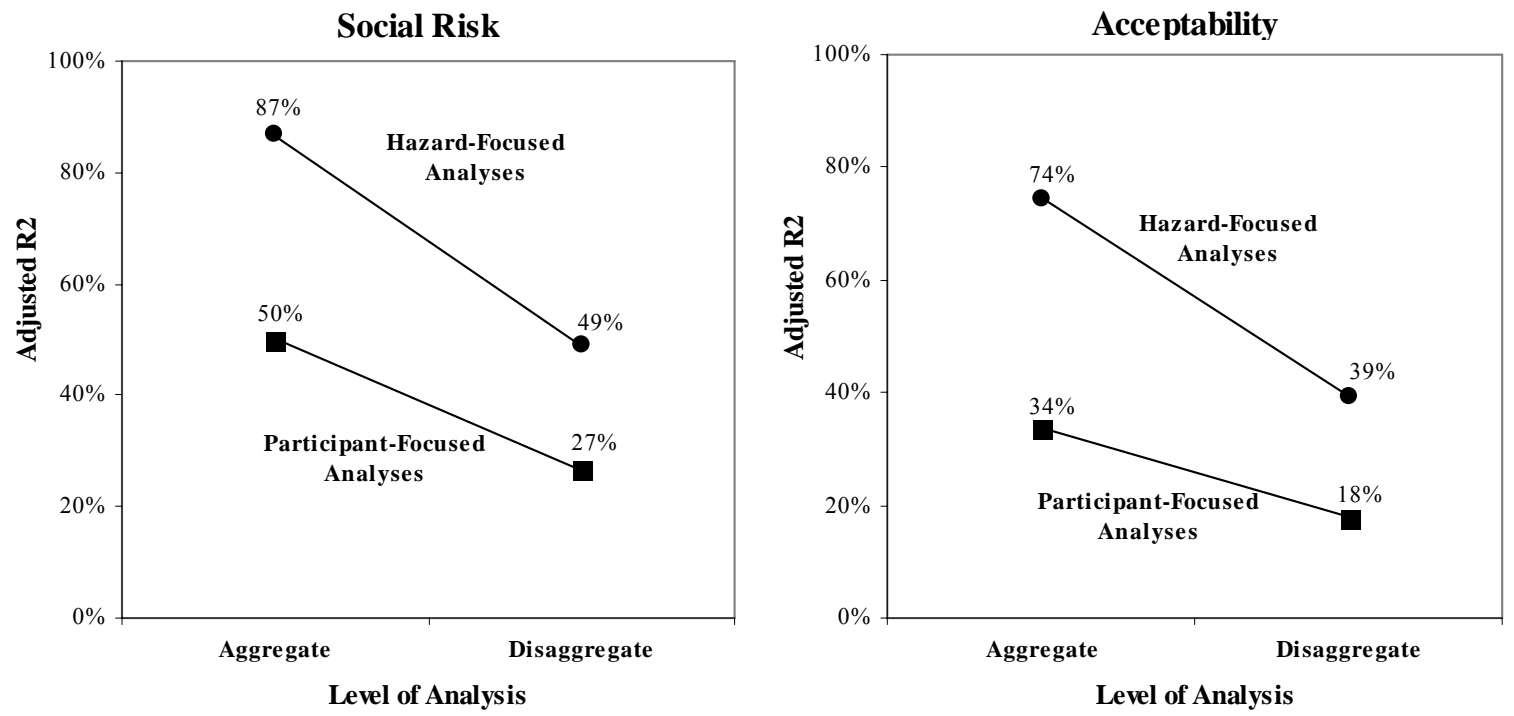

Figure 3. Percentages of variance explained in social-risk judgments (left panel) and acceptability judgments (right panel) for the four combinations of the level of analysis (aggregate or disaggregate) and the focus of analysis (hazards or participants). 

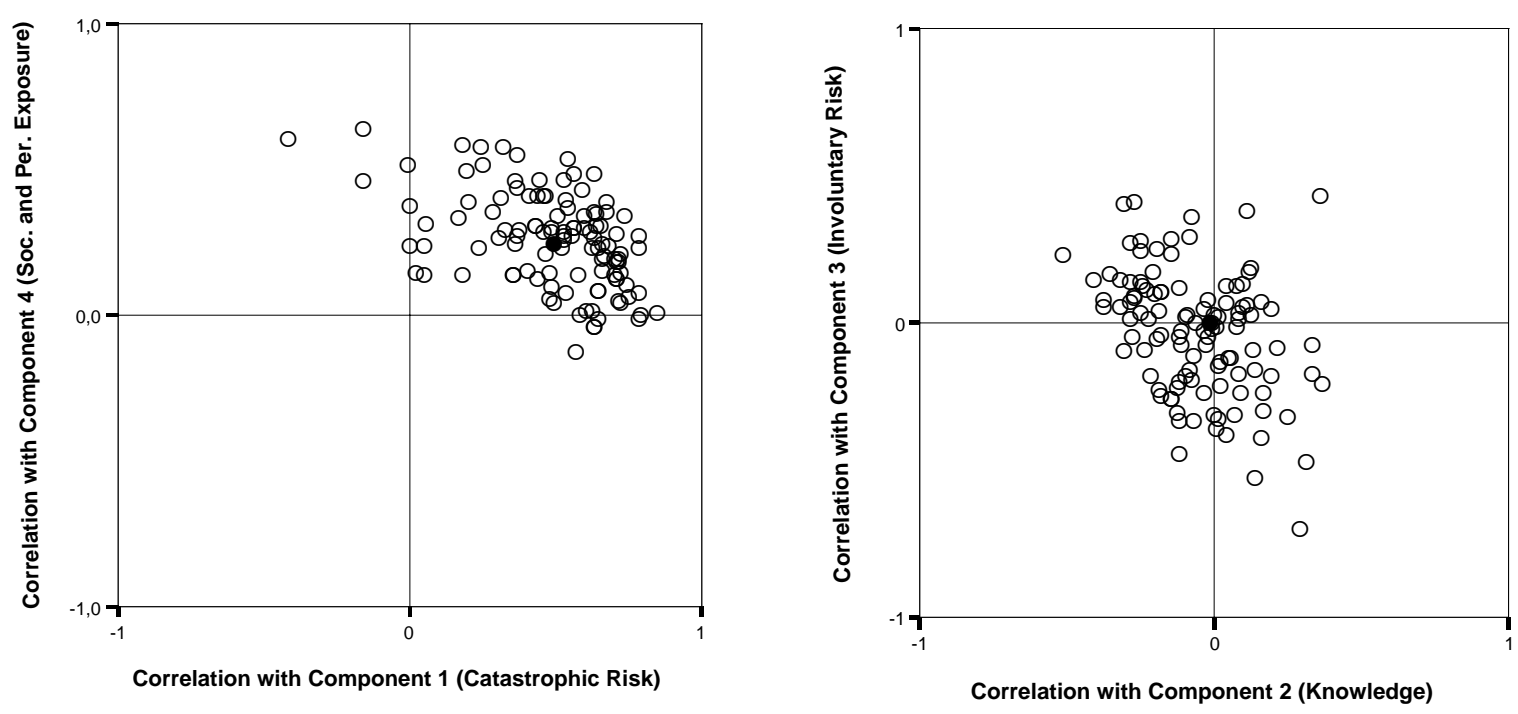

Figure 4. Individuals' judgments of social risk plotted in the psychometric space from the traditional aggregate-level hazard-focused analysis. Open circles represent the endpoints of individuals' social-risk vectors in this space. The $\mathrm{x}$ and $\mathrm{y}$ coordinates for each of these endpoints are equal to the correlations between a participant's social-risk judgments and the horizontal and vertical components, respectively. The filled circle in each panel represents the mean of the endpoints of participants' social-risk vectors. 


\section{References}

Arabie, P., and Maschmeyer, C. (1988). Some current models for the perception and judgment of risk. Organizational Behavior and Human Decision Processes, 41, 300329.

Barnett, J., and Breakwell, G. M. (2001). Risk Perception and Experience: Hazard Personality Profiles and Individual Differences. Risk Analysis, 21(1), 171-177.

Bastide, S., Moatti, J.-P., Pages, J.-P., and Fagnani, F. (1989). Risk Perception and the Social Acceptability of Technologies: The French Case. Risk Analysis, 9(2), 215-223.

Böhm, G. (2003). Emotional reactions to environmental risks: Consequential versus ethical evaluation. Journal of Environmental Psychology, 23, 199-212.

Böhm, G., and Pfister, H. R. (2000). Action tendencies and characteristics of environmental risks. Acta Psychologica, 104, 312-337.

Boholm, A. (1998). Comparative Studies of Risk Perception: A Review of Twenty Years of Research. Journal of Risk Research, 1(2), 135-163.

Bouyer, M., Bagdassarian, S., Chaabanne, S., and Mullet, E. (2001). Personality correlates of risk perception. Risk Analysis, 21, 457-465.

Bronfman, N. C., and Cifuentes, L. A. (2003). Risk Perception in a Developing Country: The Case of Chile. Risk Analysis, 23(6), 1271-1285.

Brown, T. C., Peterson, G. L., Brodersen, R. M., Ford, V., and Bell, P. A. (2005). The judged seriousness of an environmental loss is a matter of what caused it. Journal of Environmental Psychology, 25, 13-21.

Bulte, E., Gerking, S., List, J. A., and De Zeeuw, A. (2005). The effect of varying the causes of environmental problems on stated WTP values: Evidence from a field study. Journal of Environmental Economics and Management, 49, 330-342.

Dake, K. (1991). Orienting Dispositions in the Perception of Risk: An Analysis of Contemporary Worldviews and Cultural Biases. Journal of Cross-Cultural Psychology, 22(1), 61-82.

DeKay, M. L., Florig, H. K., Fischbeck, P. S., Morgan, M. G., Morgan, K. M., Fischhoff, B., et al. (2001). The Use of Public Risk Ranking in Regulatory Development. In P. S. Fischbeck and R. S. Farrow (Eds.), Improving Regulation: Cases in Environment, Health, and Safety (pp. 208-230). Washington, DC: Published by Resources for the Future.

DeKay, M. L., and McClelland, G. H. (1996). Probability and utility components of endangered species preservation programs. Journal of Experimental Psychology: Applied, 2, 60-83.

Dosman, D. M., Adamowicz, W. L., and Hrudey, S. E. (2001). Socioeconomic Determinants of Health -and Food Safety- Related Risk Perceptions. Risk Analysis, 21(2), 307-317.

Eiser, J. R., Hannover, B., Mann, L., Morin, M., Van der Pligt, J., and Webley, P. (1990). Nuclear Attitudes after Chernobyl: A Cross-National Study. Journal of Environmental Psychology, 10, 101-110. 
Englander, T., Farago, K., and Slovic, P. (1986). Comparative Analysis of Risk Perception in Hungary and the United States. Social Behavior, 1, 55-66.

Fife-Schaw, C., and Rowe, G. (1996). Public Perceptions of Everyday Food Hazards: A Psychometric Study. Risk Analysis, 16(4), 487-499.

Fife-Schaw, C., and Rowe, G. (2000). Extending the application of the psychometric approach for assessing public perceptions of food risk: some methodological considerations. Journal of Risk Research, 3(2), 167-179.

Fischhoff, B., Bostrom, A., and Quadrel, M. J. (1997). Risk Perception and Communication. In R. Detels, W. W. Holland, J. McEwen and G. S. Omenn (Eds.), Oxford Textbook of Public Health (Vol. 2, pp. 987-1002). New York.

Fischhoff, B., Slovic, P., and Lichtenstein, S. (1982). Lay Foibles and Expert Fables in Judgments About Risk. The American Statistician, 36(3), 240-255.

Fischhoff, B., Slovic, P., Lichtenstein, S., Read, S., and Combs, B. (1978). How Safe is Safe Enough? A Psychometric Study of Attitudes Towards Technological Risks and Benefits. Policy Sciences, 9, 127-152.

Florig, H. K., Morgan, M. G., Morgan, K. M., Jenni, K. E., Fischhoff, B., Fischbeck, P. S., et al. (2001). A Deliberative Method for Ranking Risks (I): Overview and Test-Bed Development. Risk Analysis, 21(5), 913-921.

Flynn, J., Slovic, P., and Mertz, C. K. (1994). Gender, Race, and Perception of Environmental Health Risks. Risk Analysis, 14(6), 1101-1108.

Gardner, G. T., and Gould, L. C. (1989). Public Perceptions if the Risks and Benefits of Technology. Risk Analysis, 9(2), 225-242.

Gardner, G. T., Tiemann, A. R., Gould, L. R., DeLuca, D. R., Doob, L. W., and Stolwijk, J. A. J. (1982). Risk and Benefit Perceptions, Acceptability Judgments, and Self-Reported Actions Toward Nuclear Power. Journal of Social Psychology, 116, 179197.

Goszczynska, M., Tyszka, T., and Slovic, P. (1991). Risk Perception in Poland: A Comparison with Three Other Countries. Journal of Behavioural Decision Making, 4, 179-193.

Harding, C. M., and Eiser, J. R. (1984). Characterizing the Perceived Risks and Benefits of Some Health Issues. Risk Analysis, 4, 131-141.

Hermand, D., Karsenty, S., Py, Y., Guillet, L., Chauvin, B., Simeone, A., et al. (2003). Risk Target: An Interactive Context Factor in Risk Perception. Risk Analysis, 23(4), 821-828.

Hinman, G. W., Rosa, E. A., Kleinhesselink, R. R., and Lowinger, T. C. (1993). Perceptions of Nuclear and Other Risks in Japan and the United States. Risk Analysis, 13, 449-455.

Irwin, J. R., Jones, L. E., and Mundo, D. (1996). Risk perception and victim perception: The judgment of HIV cases. Journal of Behavioral Decision Making, 9, 1-22.

Jenni, K. E. (1997). Attributes for Risk Evaluation. Unpublished Unpublished doctoral dissertation, Carnegie Mellon University, Pittsburgh, PA. 
Jianguang, Z. (1994). Environmental Hazards in the Chinese Public's Eyes. Risk Analysis, 14(2), 163-167.

Jones, K., and Klien, H. (1999). Lessons From 12 Years of Comparative Risk Projects. Annual Review of Public Health, 20, 159-172.

Kahneman, D., and Ritov, I. (1994). Determinants of Stated Willingness to Pay for Public Goods: A Study of the Headline Method. Journal of Risk and Uncertainty, 9, 538.

Karpowicz-Lazerg, C., and Mullet, E. (1993). Societal Risk as Seen by the French Public. Risk Analysis, 13, 253-258.

Keown, C. F. (1989). Risk Perceptions of Hong Kongese vs. Americans. Risk Analysis, 9(3), 401-405.

Kiers, H. A. L., and Van Mechelen, I. (2001). Three-way component analysis: Principles and illustrative application. Psychological Methods, 6, 84-110.

Kleinhesselink, R., and Rosa, E. (1991). Cognitive Representations of Risk Perceptions: A Comparison of Japan and the United States. Journal of Cross-Cultural Psychology, 22(1), 11-28.

Kraus, N. N., and Slovic, P. (1988). Taxonomic Analysis of Perceived Risk: Modeling Individual and Group Perceptions Within Homogeneous Hazard Domains. Risk Analysis, 8(3), 435-455.

Kuyper, H., and Vlek, C. (1984). Contrasting risk judgments among interest groups. Acta Psychologica, 56, 205-218.

Langford, I. H., Marris, C., McDonald, A.-L., Goldstein, H., Rasbash, J., and O'Riordan, T. (1999). Simultaneous Analysis of Individual and Aggregate Responses in Psychometric Data Using Multilevel Modeling. Risk Analysis, 19(4), 675-683.

Lazo, J. K., Kinnell, J. C., and Fisher, A. (2000). Expert and Layperson Perceptions of Ecosystem Risk. Risk Analysis, 20(2), 179-193.

Marris, C., Langford, I., Saunderson, T., and O'Riordan, T. (1997). Exploring the Psychometric Paradigm: Comparison Between Aggregate and Individual Analyses. Risk Analysis, 17(3), 303-312.

Marris, C., Langford, I. H., and O'Riordan, T. (1998). A Quantitative Test of the Cultural Theory of Risk Perceptions: Comparison with the Psychometric Paradigm. Risk Analysis, 18(5), 635-647.

McDaniels, T. L., Axelrod, L. J., Cavanagh, N. S., and Slovic, P. (1997). Perception of Ecological Risk to Water Environments. Risk Analysis, 17(3), 341-352.

McDaniels, T. L., Axelrod, L. J., and Slovic, P. (1995). Characterizing Perception of Ecological Risk. Risk Analysis, 15(5), 575-588.

McDaniels, T. L., Axelrod, L. J., and Slovic, P. (1996). Perceived Ecological Risks of Global Change: A psychometric comparison of causes and consequences. Global Environmental Change, 6(2), 159-171. 
Minard, R. A., Jr. (1996). CRA and the States: History, Politics, and Results. In J. C. Davies (Ed.), Comparing Environmental Risks: Tools for Setting Government Priorities (pp. 23-61). Washington, DC: Resources for the Future.

Morgan, K. M., DeKay, M. L., Fischbeck, P. S., Morgan, M. G., Fischhoff, B., and Florig, H. K. (2001). A Deliberative Method for Ranking Risks (II): Evaluation of Validity and Agreement Among Risk Managers. Risk Analysis, 21(5), 923-937.

Morgan, M. G., Fischhoff, B., Lave, L., and Fischbeck, P. (1996). A Proposal for Ranking Risk within Federal Agencies. In J. C. Davies (Ed.), Comparing Environmental Risks: Tools for Setting Government Priorities (pp. 111-147): Resources for the Future: Washington, DC.

Nyland, L. G. (1993). Risk Perception in Brazil and Sweden. (No. Rhizikon Report Number 15): Rhizikon Risk Research. Center for Risk Research, Stockholm School of Economics.

Peters, E., and Slovic, P. (1996). The role of affect and worldviews as orienting dispositions in the perception and acceptance of nuclear power. Journal of Applied Social Psychology, 26, 1427-1453.

Poumadere, M., Mays, C., Slovic, P., Flynn, J., and Johnson S. (1995). What Lies Behind Public Acceptance? Comparison of US and French Perceptions of the Nuclear Power Option. In The Nuclear Power Option. Proceedings of an International Conference on the Nuclear Power Option (pp. 393-405). Vienna.

Rohrmann, B. (1994). Risk Perception of Different Societal Groups: Australian Findings and Cross-National Comparison. Australian Journal of Psychology, 46, 150163.

Savadori, L., Savio, S., Nicotra, E., Rumiati, R., Finucane, M., and Slovic, P. (2004). Expert and Public Perception of Risk From Biotechnology. Risk Analysis, 24(5), 12891300.

Schütz, H., and Wiedemann, P. M. (1998). Judgments of Personal and Environmental Risks of Consumer Products: Do They Differ? Risk Analysis, 18(1), 119-129.

Siegrist, M., Keller, C., and Kiers, A. L. H. (2005). A New Look at the Psychometric Paradigm of Perception of Hazards. Risk Analysis, 25(1), 209-220.

Sjöberg, L. (1996). A Discussion of the Limitations of the Psychometric and Cultural Theory Approaches to Risk Perception. Radiation Protection Dosimetry, 68, 219-225.

Sjöberg, L. (1998). Why Do People Demand Risk Reduction? In S. Lydersen, G. K. Hansen and H. A. Sandtorv (Eds.), ESREL-98: Safety and Reliability (pp. 751-758): A. A. Balkema.

Sjöberg, L. (1999). The Psychometric Paradigm Revisited. Paper presented at the Royal Statistical Society Conference, University of Warwick, July.

Sjöberg, L. (2000). Factors in Risk Perception. Risk Analysis, 20(1), 1-11.

Sjöberg, L. (2002). Are Received Risk Perception Models Alive and Well? Risk Analysis, 22(4), 665-669.

Sjöberg, L., and Wåhlberg, A. (2002). Risk Perception and New Age Beliefs. Risk Analysis, 22(4), 751-764. 
Slovic, P. (1987). Perception of Risk. Science, 236, 280-285.

Slovic, P., Fischhoff, B., and Lichtenstein, S. (1980). Facts and Fears: Understanding Perceived Risk. In R. C. Schwing and W. A. Albers (Eds.), Societal Risk Assessment: How Safe is Safe Enough? (pp. 181-216). New York: Plenum Press.

Slovic, P., Fischhoff, B., and Lichtenstein, S. (1985). Characterizing Perceived Risk. In R. W. Kates, C. Hohenemser and J. X. Kasperson (Eds.), Perilous Progress: Managing the Hazards of Technology (pp. 91-125). Boulder, Colorado: Westview Press.

Slovic, P., Fischhoff, B., and Lichtenstein, S. (1986). The Psychometric Study of Risk Perception. In V. T. Covello, J. Menkes and J. Mumpower (Eds.), Risk Evaluation and Management (pp. 3-24). New York.

Teigen, K. H., Brun, W., and Slovic, P. (1988). Societal Risks as Seen by the Norwegian Public. Journal of Behavioural Decision Making, 1, 111-130.

Trumbo, C. W. (1996). Examining Psychometrics and Polarization in a Single-Risk Case Study. Risk Analysis, 16(3), 429-438.

Vlek, C., and Stallen, P.-J. (1981). Judging Risks and Benefits in the Small and in the Large. Organizational Behavior and Human Performance, 28, 235-271.

Wagenaar, W. A., Keren, G., and Pleit-Kuiper, A. (1984). The Multiple Objectives of Gamblers. Acta Psychologica, 56, 167-178.

Wiegman, O., Gutteling, J. M., and Cadet, B. (1995). Perception of Nuclear Energy and Coal in France and the Netherlands. Risk Analysis, 15(4), 513-521.

Willis, H. H., and DeKay, M. L. (2005). The roles of group membership, beliefs, and norms in ecological risk perception. Manuscript submitted for publication.

Willis, H. H., DeKay, M. L., Fischhoff, B., and Morgan, M. G. (2005). Aggregate, Disaggregate, and Hybrid Analyses of Ecological Risk Perceptions. Risk Analysis, 25(2), $405-428$.

Willis, H. H., DeKay, M. L., Morgan, M. G., Florig, H. K., and Fischbeck, P. S. (2004). Ecological Risk Ranking: Development and Evaluation of a Method for Improving Public Participation in Environmental Decision Making. Risk Analysis, 24(2), 363-378. 